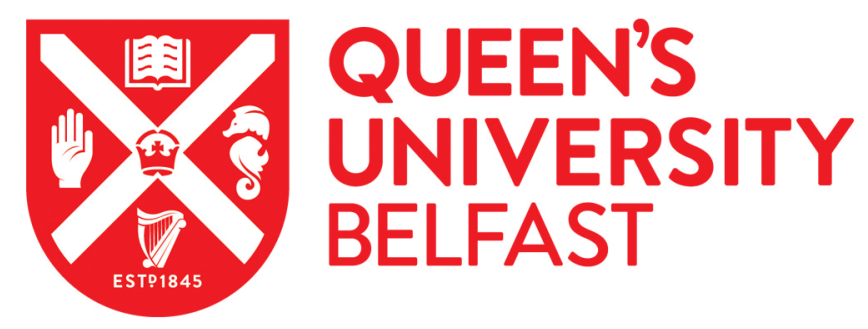

\title{
Investigation of chip formation and fracture toughness in orthogonal cutting of UD-CFRP
}

Li, H., Qin, X., He, G., Jin, Y., Sun, D., \& Price, M. (2016). Investigation of chip formation and fracture toughness in orthogonal cutting of UD-CFRP. International Journal of Advanced Manufacturing Technology, 82(5-8), 10791088. https://doi.org/10.1007/s00170-015-7471-x

Published in:

International Journal of Advanced Manufacturing Technology

Document Version:

Peer reviewed version

Queen's University Belfast - Research Portal:

Link to publication record in Queen's University Belfast Research Portal

Publisher rights

(C) Springer-Verlag London 2015

This work is made available online in accordance with the publisher's policies. Please refer to any applicable terms of use of the publisher.

\section{General rights}

Copyright for the publications made accessible via the Queen's University Belfast Research Portal is retained by the author(s) and / or other copyright owners and it is a condition of accessing these publications that users recognise and abide by the legal requirements associated with these rights.

Take down policy

The Research Portal is Queen's institutional repository that provides access to Queen's research output. Every effort has been made to ensure that content in the Research Portal does not infringe any person's rights, or applicable UK laws. If you discover content in the Research Portal that you believe breaches copyright or violates any law, please contact openaccess@qub.ac.uk. 


\title{
Investigation of chip formation and fracture toughness in orthogonal cutting of UD-CFRP
}

\author{
Hao Li · Xuda Qin* · Gaiyun He · Yan Jin · Dan Sun · Mark Price
}

Received: date / Accepted: date

\begin{abstract}
Features of chip formation can inform the mechanism of a machining process. In this paper, a series of orthogonal cutting experiments were carried out on unidirectional carbon fiber reinforced polymer (UD-CFRP) under cutting speed of $0.5 \mathrm{~m} / \mathrm{min}$. The specially designed orthogonal cutting tools and high-speed camera were used in this paper. Two main factors are found to influence the chip morphology, namely the depth of cut (DOC) and the fiber orientation (angle $\theta$ ), and the latter of which plays a more dominant role. Based on the investigation of chip formation, a new approach is proposed for predicting fracture toughness of the newly machined surface and the total energy consumption during CFRP orthogonal cutting is introduced as a function of the surface energy of machined surface, the energy consumed to overcome friction, and the energy for chip fracture. The results show that the proportion of energy spent on tool-chip friction is the greatest, and the proportions of energy spent on creating new surface decrease with the increasing of fiber angle.
\end{abstract}

Keywords UD-CFRP · Orthogonal cutting · Fracture toughness · Chip formation

Hao Li

E-mail: haolitju@tju.edu.cn

Xuda Qin*

Key Laboratory of Mechanism Theory and Equipment Design of Ministry of Education, Tianjin University, Tianjin 300072, China

Tel.: +086 13920512761

Fax: +08622 27406260

E-mail: qxd@tju.edu.cn

Gaiyun He

Yan Jin · Dan Sun · Mark Price

School of Mechanical and Aerospace Engineering, Queens University Belfast, United Kingdom BT9 5AH

\section{Introduction}

Carbon fiber reinforced plastic (CFRP) composite consist$s$ of carbon fibers encapsulated by plastic matrix. The carbon fibers are responsible for carrying load, while the matrix serves to distribute, hold, and protect the fibers as well as to transmit the load [1-3]. This unique material structure contributes to the enhanced mechanical and structural properties and made CFRP an ideal substitute for metals. CFRP composites have many superior properties, such as high strength to weight ratio, excellent fatigue and creep resistance, low frictional coefficient, good toughness and damage tolerance, high wear and corrosion resistance as well as dimensional stability, and high vibration damping ability $[4,5]$. Due to their superior properties, CFRP composites become very attractive in a variety of applications especially in the field of aerospace, aeronautical and automotive industry. Components made from CFRP composites are mostly produced in near-net-shape. However, secondary manufacturing processes such as milling and drilling are often required for imparting the dimensional tolerances and assembly of composite parts [6-8].

Orthogonal cutting refers to the cutting process in which the tool edge is perpendicular to the direction of tool travel. Although it is uncommon in conventional industrial machining process, the operation provides an essential understanding of the deformation mechanism of machined CFRP materials. Machinability of CFRP mainly depends on the properties of fibers and matrix and their combined effects on chip formation mechanisms [9]. Koplev et al. [10] discussed the chip size and fracture with regard to fiber orientation using quasi-static orthogonal cutting tests of carbon/epoxy composites. Arola et al. [11] correlated chip formation mechanisms with fiber orientation and tool geometry when orthogonally trimming graphite/epoxy composites using PCD tools. Chip formation was found to be predominately dependent on fiber orientation. Nayak et al. [12] have utilized the 
orthogonal cutting trials for inspecting the volume of material removed when machining glass/epoxy using HSS tool. Zitoune et al. [13] carried out similar experiments on unidirectional type of carbon/epoxy using the K20 carbide tool. It can be concluded from these reports that the machinability of CFRP is strongly dependent on the machining direction. When machining laminates with $0^{\circ}$ fiber orientation, the compressive stress induced by the tool edge causes the fibers to break perpendicularly to their axes under buckling or bending. In classic fracture mechanics, the crack formation mechanism is divided into three modes. Mode I: external load is the normal stress which is perpendicular to the plane of crack, and the relative displacement of crack plane is perpendicular to the crack plane; Mode II: external load is the shear stress which is perpendicular to the edge of crack and located in cracking plane. When machining laminates with fiber orientation $90^{\circ} \leq \theta<180^{\circ}$ at a positive rake angle, Mode I fracture initiates along the fiber-matrix interface causing delaminated material peel and slide on the rake face. When the fiber orientation is $0^{\circ} \leq \theta<90^{\circ}$, Mode II fiber failure occurs under compressive shear [6]. However, the influence of cutting parameters on chip morphology has not been elaborated in detail.

Cutting process models for composite materials have been developed over the past decades [14-18], and many of these models are based on the Merchant's single shear plane model [19], which was originally developed for metallic materials.

However,the CFRP cutting process is quite different as compared to metal cutting [20]. Several studies have adopted the Merchant shear plane theory for developing the constitutive approach. Everstine et al. [15] developed the first theoretical model on the cutting of FRP materials. The composite is treated as incompressible and inextensible along the fiber direction and the fibers are continuously distributed. The authors proposed a deformation field in the chip analogous to the field of the thick zone model with rupture and separation occurring ahead of the tool. Bhatnagar et al. [16] have presented an approach based on the Merchants theory and experimental validation on CFRP of fiber angle $0^{\circ} \leq \theta<90^{\circ}$. In this model, the authors assumed the shear plane angle to be the fiber angle where failure occurs. Zhang et al. [17] developed a mechanical model to predict cutting forces during the orthogonal cutting of unidirectional FRP, For fiber orientations below $90^{\circ}$, the cutting zone has been devided into three regions: chipping, pressing and bouncing. Jahromi et al. [18] developed an analytical model using elastoplastic matrix behavior to predict cutting forces during orthogonal cutting of unidirectional FRP $\left(90^{\circ} \leq \theta<180^{\circ}\right)$ and the authors distinguished three chip formation mechanisms: fiber bending, fiber microbuckling and matrix shearing. And recently, the microscopic mechanism based on force prediction in orthogonal cutting of UD-
CFRP was elaborated with analyzing the representative volume element [3]. However, due to the distinctively different material properties, it is difficult to accurately predict accurately the failure and identify the chip formation mechanisms for composites, therefore, the new analysis method is required to better understand the material removal and chip formation processes for CFRP.

With the proposition and development of the fracture energy for newly generated surfaces, the cutting force balance model and energy conservation equation have been improved. Atkins [21] concluded that the work of fracture can be a significant component of total cutting work and established the cutting force equation by considering the surface energy as well as the plastic deformation in the primary shear zone and the friction along the tool-chip interface. Astokhov et al. [22] presented a methodology for practical estimation of cutting force and cutting power. Recently, Williams et al. [23] proposed a mechanical cutting methodology for the measurement of fracture toughness and it is validated for several types of polymers. The approach is proven to be effective while avoiding the problems associated with crack blunting. However, to date, the analysis on fracture toughness and energy conservation has yet been developed for CRFP machining processes.

In this paper, detailed experimental investigation on UDCFRP orthogonal cutting and chip formation mechanism are presented. The shear angle in orthogonal cutting with $0^{\circ}-$ $75^{\circ}$ fiber orientation has been obtained by examining the morphology feature of chipping region. A new method is introduced for measuring fracture toughness of newly machined CFRP based on the Williams model [23], which led to the formulation of the energy consumption model. Finally, the energy conservation analysis in the CFRP cutting process is also discussed in details.

\section{Experiments}

Fiber orientation angle is firstly investigated because of its great influence on chip formation in CFRP machining [16]. The fiber orientation angle, $\theta$, is defined in Fig. 1. The tool feeding direction (cutting direction) is defined as the initial position $\left(0^{\circ}\right)$. When the tool rotates and coincides with the fiber orientation, the angle of rotation will be defined as the fiber orientation angle, $\theta$. In this paper, the selected fiber angles were: $0^{\circ}, 15^{\circ}, 30^{\circ}, 45^{\circ}, 60^{\circ}, 75^{\circ}, 90^{\circ}, 120^{\circ}, 135^{\circ}$ and $150^{\circ}$.

The orthogonal cutting tests were carried out using specially designed cutting tools on a JOHNFORD (VMC-850) vertical machining center, as shown in Figure 2. The tool matrix material is solid tungsten carbide (WC-8\%Co), and the cutting edge length is $7 \mathrm{~mm}$ which is greater than the workpiece thickness $(5 \mathrm{~mm})$, thus, the tool can effectively cut through the entire workpiece during orthogonal cutting 


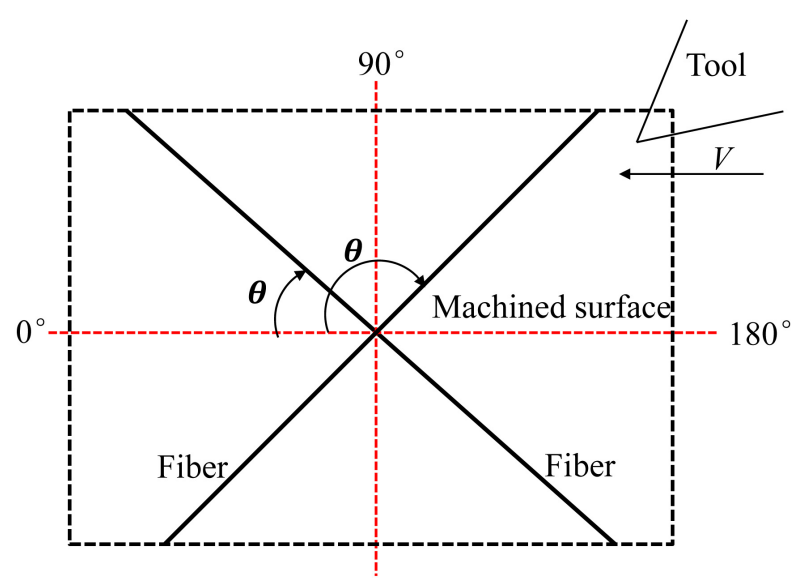

Fig. 1 Schematic definition of fiber angle $\theta$ in CFRP orthogonal cutting

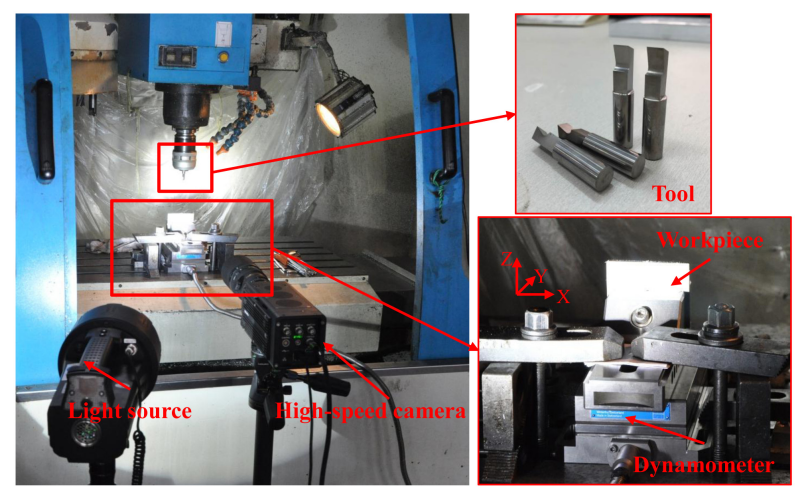

Fig. 2 Experimental set-ups of CFRP orthogonal cutting

process. The rake angle and clearance angle are $25^{\circ}$ and $20^{\circ}$, respectively. Meanwhile, in order to ensure the sharpness of cutting edge, the tool is uncoated. The tool spindle was locked to ensure no rotational motion during the tests. Under the selected machine setting the tool can only feed in the horizontal direction, and orthogonal cutting of different fiber orientations can be achieved by using different workpieces. The CFRP material was made from unidirectional prepreg with carbon fiber and epoxy resin matrix, and the material properties can be found in Table 1.

A Kistler three-direction stationary dynamometer (9257) with supporting Kistler charge amplifier (type 5070) was used, and data acquisition board and Kistler software were deployed for X and Y direction cutting force measurement. During the orthogonal cutting, high-speed camera images were captured at 500pps. In order to obtain better quality images, a high power light source was used, shown in Fig. 2. The experimental condition has been defined following literature $[12,13,24,25]$ and details are listed in Table 2.

\section{Experimental observation of chip formation}

In CFRP, the ultimate strength of carbon fibers is much larger than that of the resin matrix, hence the fibers imposes most influence on the cutting process. Since carbon fiber belongs to elastic-brittle materials, its deformation during cutting is similar to other brittle materials. Different fiber orientation leads to anisotropic material properties, which in turn leads to different material deformation and chip formation mechanism. In CFRP cutting (especially for unidirectional CFRP), the cracking in workpiece always forms ahead of the cutting tool. Mode I and II are found to be the main crack propagation modes for CFRP orthogonal cutting process [6].

Depending on the fiber orientation, cutting process characteristics have been categorized into four types [26]: $0^{\circ}$, $15^{\circ}-75^{\circ}, 75^{\circ}-90^{\circ}$ and $90^{\circ}-180^{\circ}$ fiber orientation. The analysis of chip formation in this study has also based on this classification.

\subsection{Fiber angle $\theta=0^{\circ}$}

The images of chip formation at $0^{\circ}$ fiber angle is shown in Fig. 3. It is clearly seen that the chip morphology is dependent on the DOC $\left(a_{c}\right)$. When $a_{c}=0.1 \mathrm{~mm}$ (Fig. 3a and b), the chips are powder-like. Material crushing or peeling took place at the tool tip, leading to fiber bucking/bending fracture. For $a_{c}=0.5 \mathrm{~mm}$ (Fig. $4 \mathrm{c}$ and d), the crack forms and propagates along the fiber direction ahead of the tool. In other words, the tool is cutting on a surface that has already experienced bending and cracking. The DOC in this second cut zone (red circle in Fig. 3d) was no longer $0.5 \mathrm{~mm}$, but much shallower in the second cut zone.
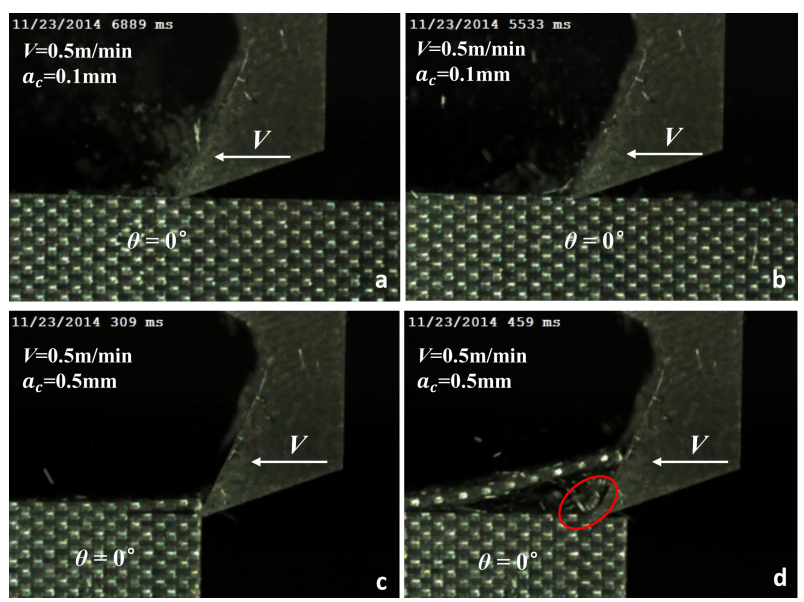

Fig. 3 Chip formation process in UD-CFRP orthogonal cutting $(\theta=$ $\left.0^{\circ}\right)$

As the tensile strength of the matrix $(\sim 50 \mathrm{MPa})$ is much lower than the compressive strength of the fiber, separation of the two phases occurs at of the tool tip and Mode I fracture initiates along the fiber direction causing a layer of material to peel and to slide on the rake face. The tool continues 
Table 1 Material properties of T700/E765 epoxy resin matrix composites

\begin{tabular}{lllll}
\hline Tensile Strength, Yield & Tensile Modulus & Compressive Strength & Compressive Modulus & Shear Strength \\
\hline $2300 \mathrm{MPa}$ & $125 \mathrm{GPa}$ & $738 \mathrm{MPa}$ & $123 \mathrm{GPa}$ & $39.3 \mathrm{MPa}$ \\
\hline
\end{tabular}

Table 2 Experiment condition

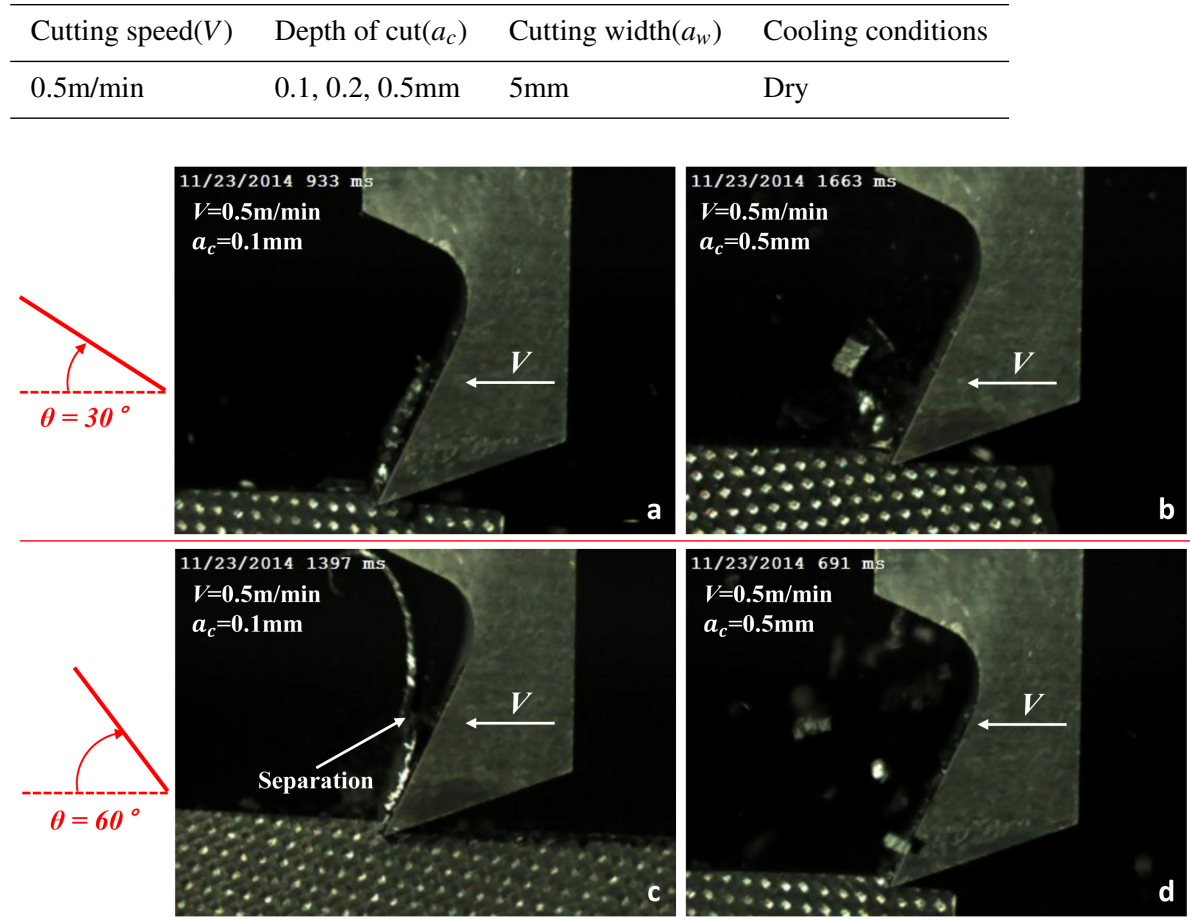

Fig. 4 Chip formation in UD-CFRP orthogonal cutting $\left(15^{\circ} \leq \theta<75^{\circ}\right)$

to travel causing an increased bending stress on the peeled layer. The chip eventually breaks in direction perpendicularly to the fiber when the bending stress exceeds the bending limit of fiber, resulting in a blocky chip. Nevertheless, the powder-like chips were observed in the second cut zone, similar to what has been seen in Fig. 3 (a, b). The irregular powder-like chips consist of fiber and matrix powders resulting from the shear stress along the fiber direction (Mode II fracture) and the materials buckling. The thickness of blocky chip (caused by Mode I fracture) is dependent on DOC, and its length is dependent on the rake angle of the tools and the fibers bending stress.

\subsection{Fiber angle $15^{\circ} \leq \theta<75^{\circ}$}

Fig. 4 illustrates the chip formation process for $15^{\circ} \leq \theta<$ $75^{\circ}$. In this case, compression imposed by the cutting tool edge induced shear stress perpendicular to the axis of the fiber. When the shear stress exceeds the ultimate shear strength of carbon fiber, fiber fracture occurs. After that, the failed fiber slides along in the fiber direction under the compression induced by the cutting tool until a chip is formed (Mode
II fracture). Therefore, when the fiber orientation is $15^{\circ} \leq$ $\theta<75^{\circ}$ (only $\theta=30^{\circ}$ and $\theta=60^{\circ}$ shown in Fig. 4), microfracture occurs due to the compression-induced shear across the fiber axis and the interfacial shearing along the fiber direction, which eventually causes chip separation from the workpiece.

For this set of experiments, the DOC is also found having a significant influence on the morphology of chip. When the depth of cut is relatively low $\left(a_{c}=0.1 \mathrm{~mm}\right)$, the morphology of chips are continuous and ribbon-like, which turn into blocky when the depth of cut is $0.5 \mathrm{~mm}$, as shown in Fig. 4. Unlike the continuous chip in metal machining, the continuous chip in CFRP orthogonal cutting is formed by weakly connected tiny chips which separate easily as the tool travels, as shown in Fig. 4 (c).

In the case of $15^{\circ} \leq \theta<75^{\circ}$, the geometrical morphology of shear plane, i.e., the separation surface between chip and workpiece, was obtained using microscope with high resolution and depth of field. Due to the slip at the fiber/matrix interfaces, no fiber breakage was observed in shear plane, as shown in Fig. 5(a). Based on the 3D coordinate value of shear zone under different fiber orientation, the value of shear angle for different $\mathrm{Y}$ position is obtained from trigono- 
a
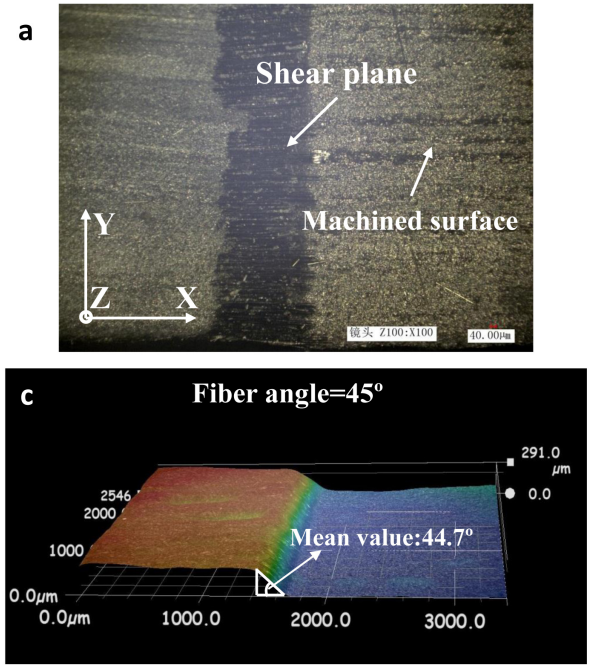
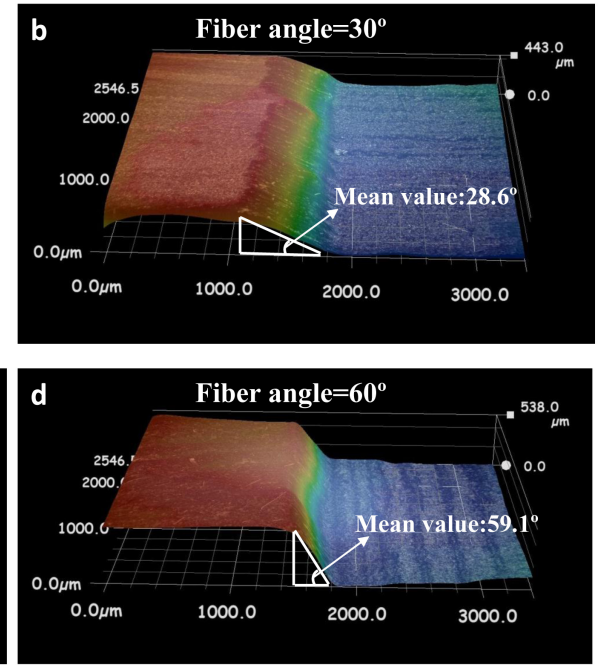

Fig. 5 Shear plane in UD-CFRP orthogonal cutting $\left(15^{\circ} \leq \theta<75^{\circ}\right)$

metric calculation. The mean shear angle corresponding to fiber angle $30^{\circ}, 45^{\circ}$ and $60^{\circ}$ were $28.6^{\circ}, 44.7^{\circ}$ and $59.1^{\circ}$, respectively, as shown in Fig. 5(b,c,d). The calculation results are closely coordinated with the corresponding fiber angles. Therefore, it can be concluded that chips are produced by shearing along the fiber direction and the shear angle can be substituted by fiber angle for $15^{\circ} \leq \theta<75^{\circ}$. This is useful for analysis of fracture toughness in Section 4 of this paper.

\subsection{Fiber angle $75^{\circ} \leq \theta<180^{\circ}$}

In the case of relatively high fiber orientation angle $\left(75^{\circ} \leq\right.$ $\theta<180^{\circ}$ ), the chip is yielded due to bending under a severe compressive loading with an out-of-plane shear resulting in an inter-laminar deformation, as shown in Fig. 6(a, b and c). Mode I fracture is not seen whereas mode II occurs as soon as the tool comes into contact with the specimen [6]. The roughness of machined surface was poor due to the $p$ resence of the micro-cracks. Some of the bent fibers failed when the bending stress exceeds the yield strength of the fiber, and this mostly occurred below the cutting edge (cutting plane) where maximum stress occurs. Other bent fibers tend to bounce back, as shown in Fig. 6(c), and this would degrade the quality of machined CFRP surface. Under this set of machining condition, the chip is continuous ribbonlike when $a_{c}=0.1 \mathrm{~mm}$, and blocky chips were produced when $a_{c}=0.2 \mathrm{~mm}$. As shown in Fig. 6(d), a catastrophic through crack was formed under a relatively larger DOC.

\section{Fracture toughness and energy distribution}

In the case of $15^{\circ} \leq \theta<75^{\circ}$, the removed material undergoes shear yielding in the direction of fiber orientation when it moves along the tool rake face during orthogonal cutting process. In this case, the fracture occurs at the tool tip where the primary shear zone contacts with the bulk material. Fig. 7 shows schematically the orthogonal cutting process where the geometric parameters of cutting zone and the cutting force between tool and chip are illustrated. The red dashed lines represents the chip separation surface in orthogonal cutting process.

As CFRP is a elastic-brittle material, and no plastic deformation takes place during the cutting process, the following equation applies,

$a_{c h}=a_{c}, V_{c}=V$

where $a_{c h}$ is the chip thickness, $a_{c}$ is the DOC, $V_{c}$ is the chip flow speed and $V$ is the tool cutting speed.

The fracture takes place at the point where the tool tip is in contact with the primary shear zone of the removed CFR$\mathrm{P}$ layer. The horizontal cutting force acting on the tool tip is the direct factor causing the removed layer to separate from the bulk material [27]. Consequently, the horizontal cutting force per unit width along the tool tip is equivalent to the materials fracture toughness $G_{c}$, the value of which can be further regarded as surface energy. As a result, the remained horizontal force per unit width between tool and chip is $\left(F_{c} / a_{w}\right)-G_{c}$, where $a_{w}$ is the cutting width. The force equation on the shear plane can be expressed as [28]

$$
\frac{F_{c}}{a_{w}}-\frac{F_{t}}{a_{w}} \tan \phi=\tau_{1} a_{c}\left(\tan \phi+\frac{1}{\tan \phi}\right)+G_{c}
$$

where $\tau_{1}$ is the shear strength of the work-piece along the fiber direction, $F_{c}$ is the horizontal cutting force and $F_{t}$ is the thrust force.

It is found that the shear plane exists along the fiber direction when $15^{\circ} \leq \theta<75^{\circ}$. Chips are produced against the cutting tool by shearing of the fiber-matrix interface along 

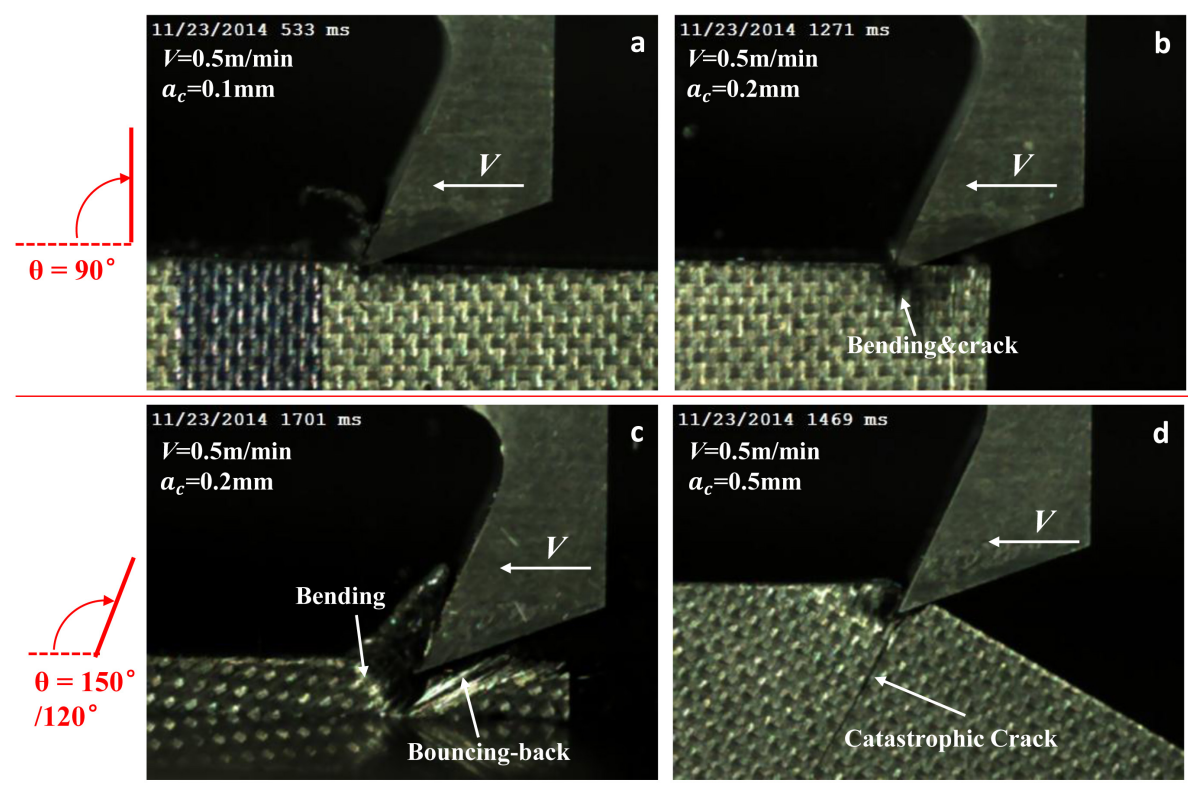

Fig. 6 Chip formation in UD-CFRP orthogonal cutting $\left(75^{\circ} \leq \theta<180^{\circ}\right)$

the fiber direction, as elaborated in section 3. Hence, the shear angle $\phi$ can be substituted by fiber angel $\theta$ and Eq.(3) giving

$\frac{F_{c}}{a_{w}}-\frac{F_{t}}{a_{w}} \tan \theta=\tau_{1} a_{c}\left(\tan \theta+\frac{1}{\tan \theta}\right)+G_{c}$

Using the value of $\tan \theta$, the measured cutting force $F_{c}$, thrust force $F_{t}$, and subsequently the values of $F_{c} / a_{w}-\left(F_{t} /\right.$ $\left.a_{w}\right) \tan \theta$ and $a_{c}(\tan \theta+1 / \tan \theta)$ under different DOCs and fiber angles can be calculated. Once $F_{c} / a_{w}-\left(F_{t} / a_{w}\right) \tan \theta$ versus $a_{c}(\tan \theta+1 / \tan \theta)$ is fitted into Eq. (3), the fracture toughness and shear strength of the workpiece can be obtained from the value of the vertical intercept and the slope of the fitted regression line.

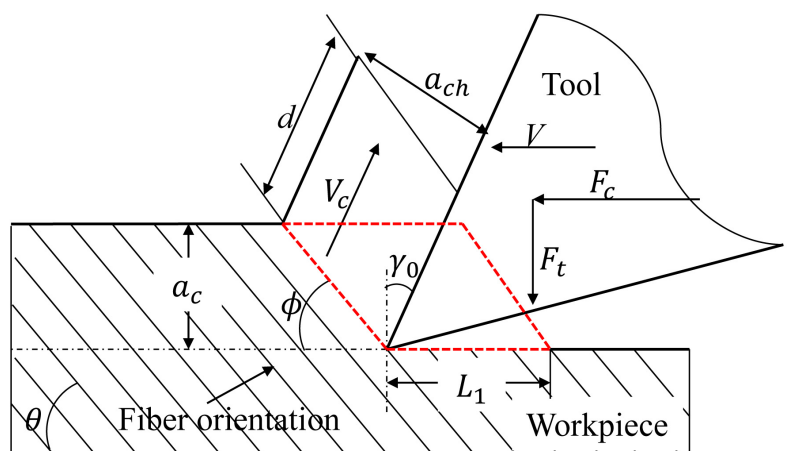

Fig. 7 Diagram of UD-CFRP orthogonal cutting model in the case of $75^{\circ} \leq \theta<180^{\circ}$

According to the cutting process of CFRP orthogonal cutting, with cutting speed $V$, the increment of external work,
$E_{\text {ext }}$, is given by $F_{c} V$. Under steady-state conditions, the energy remains unchanged and the following equation applies

$E_{\text {ext }}=E_{\text {diss }}$

where $E_{d i s s}$ is the increment of dissipated energy and can be given by,

$E_{\text {diss }}=E_{\text {fract }}+E_{\text {frict }}+E_{\text {chip }}$

where $E_{\text {fract }}, E_{\text {frict }}$ and $E_{\text {chip }}$ are the fracture energy of new surface, frictional energy on the tool-chip interface, and chip fracture energy during the chip formation process, respectively. Thus, the energy required to form a new surface (i.e. the materials fracture toughness $G_{c}$ ) is comparable with the energy consumed for plastic deformation and friction work and should not be ignored [28]. Hence in this study the new surface fracture energy is given by

$E_{\text {fract }}=G_{c} a_{w} V$

The friction force on the tool-chip interface is given by

$S=\left(F_{c}-a_{w} G_{c}\right) \sin \gamma_{0}+F_{t} \cos \gamma_{0}$

where $\gamma_{0}$ is the tool rake angle, and from Eq. (1), the friction energy on the tool-chip interface can be obtained by,

$$
\begin{aligned}
E_{\text {frict }} & =S \cdot V_{c}=S \cdot V \\
& =\left[\left(F_{c}-a_{w} G_{c}\right) \sin \gamma_{0}+F_{t} \cos \gamma_{0}\right] V
\end{aligned}
$$

The chip morphology has been analyzed in Section 3 of this paper, and the chip removal mechanism is mainly interlaminar sliding along the fiber orientation $\theta$. This fracture energy is the product of energy required for the formation of 
one fracture face and the number of fracture planes formed per unit time

$E_{\text {chip }}=E_{f r} \frac{V}{d}$

where $d$ is the chip block thickness measured directly from CFRP orthogonal cutting process, which is illustrated in Fig. 7. $E_{f r}$ is the fracture energy required for a single chip separation from a fracture plane

$E_{f r}=G_{c}^{\prime} A_{f r}$

where $G_{c}^{\prime}$ is the chip surface energy which can also be called chip fracture toughness [29]. $A_{f r}$ is the area of fracture in a shear plane, the fracture area, and can be expressed as $a_{c} a_{w} / \sin \phi$ and the chip fracture energy can be expressed as follows

$E_{c h i p}=G_{c}^{\prime} A_{f r} f=G_{c}^{\prime} \frac{a_{w} a_{c}}{\sin \phi} \frac{V}{d}=G_{c}^{\prime} \frac{a_{w} a_{c}}{\sin \theta} \frac{V}{d}$

Therefore, the energy distribution on the four portions (i.e. plastic deformation, friction, new surfaces formation and chip fracture) can be analyzed with Eq. (12).

$F_{c} V=G_{c} a_{w} V+\left[\left(F_{c}-a_{w} G_{c}\right) \sin \gamma_{0}+F_{t} \cos \gamma_{0}\right] V+G_{c}^{\prime} \frac{a_{w} a_{c}}{\sin \theta} \frac{V}{d}$

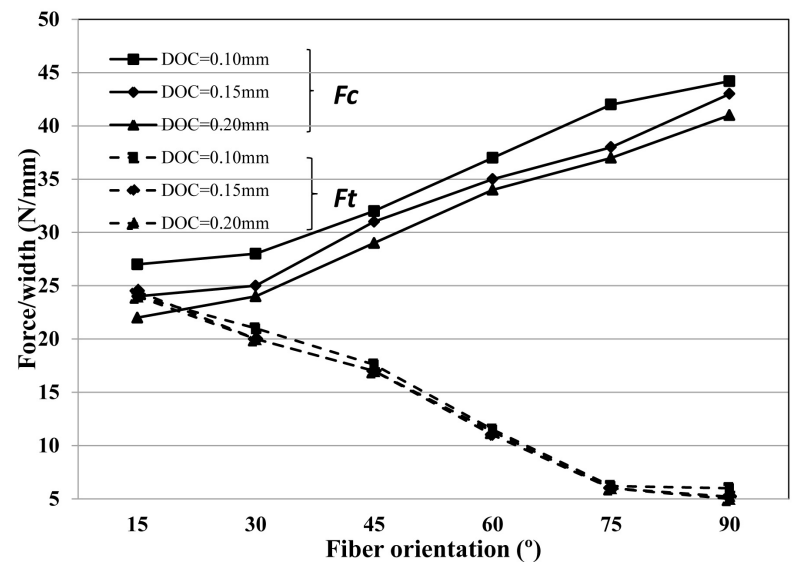

Fig. 8 Experimental results of the cutting forces $\left(F / a_{w}\right)$ with the variation of fiber orientation

\section{Results and discussion}

5.1 Shear strength and fracture toughness

As shown in Fig. 8, the principle cutting force $F_{c}$ increases with fiber orientation $\left(15^{\circ} \leq \theta<75^{\circ}\right)$ for different DOC selected. The thrust force $F_{t}$, however, is not sensitive to DOC and decreases with increasing $\theta$. Combined with the measured results of cutting force $F_{c}$, thrust force $F_{t}$ and cutting parameters under the three different DOCs for each fiber orientation $\left(15^{\circ}, 30^{\circ}, 45^{\circ}, 60^{\circ}\right.$ and $\left.75^{\circ}\right)$, five line-fittings between $F_{c} / a_{w}-\left(F_{t} / a_{w}\right) \tan \theta$ and $a_{c}(\tan \theta+1 / \tan \theta)$ are obtained based on Eq. (4), as shown in Fig. 9. The correlation coefficients $\left(R^{2}\right.$ value) of the five lines are all greater than 0.93. The fracture toughness $G_{c}$ and the shear strength $\tau_{1}$ of the workpiece material with five different $\theta$ can then be determined from the vertical intercepts and the slopes of these fitted lines. The calculation results of $G_{c}$ and $\tau_{1}$ for different is shown in Table 3.

From Table 3, it can be found that the shear strength along fiber direction is independent on fiber angle. The mean value of shear strength is $12.290 \mathrm{MPa}$, whereas the experimental measurements of fiber-matrix interface shear strength is $15-25 \mathrm{MPa}$ [30], the variation might be due to error in cutting force measurements and the effect of cutting edge radius. The fracture toughness of new machined surface $G_{c}$ of different fiber orientations are also shown in Table 3. No obvious change in $G_{c}$ can be found with increasing fiber angle, the mean value of will be used for energy conservation calculation in the following section.

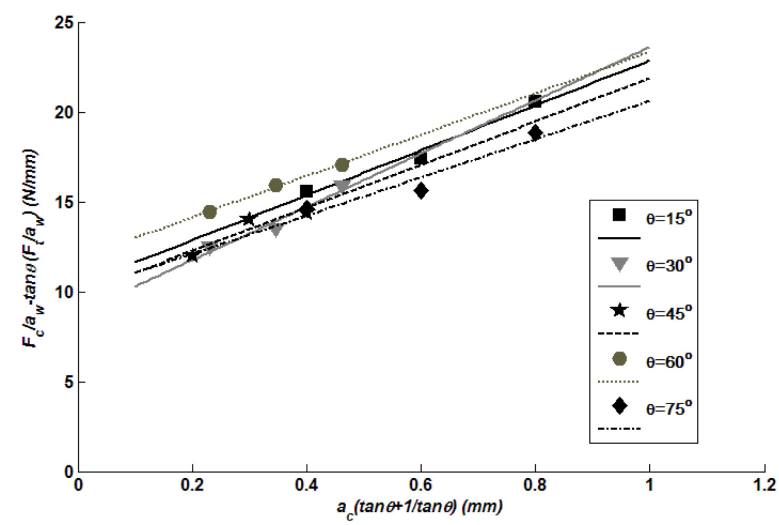

Fig. 9 Line fitting of $F_{c} / a_{w}-\left(F_{t} / a_{w}\right) \tan \theta$ vs. $a_{c}(\tan \theta+1 / \tan \theta),\left(F_{c}\right.$ : cutting force, $F_{t}$ : thrust force, $a_{w}$ : cutting width, $\theta$ : fiber angle, $a_{c}$ : uncut chip thickness)

\subsection{Energy distribution in CFRP orthogonal cutting}

The chip surface energy $G_{c}^{\prime}$ under different cutting conditions can be obtained through polynomial operation of $\mathrm{E}$ q. (12). The energy consumed during the cutting process is attributed to new surface energy, friction and chip fracture energy. Fig. 10 shows the energy distribution on these three factors for fiber angles $30^{\circ}, 45^{\circ}$ and $60^{\circ}$, respectively. When the fiber angle is $30^{\circ}$, the energy spent on the new machined 
Table 3 Results of shear strength and fracture toughness under different fiber angles

\begin{tabular}{lllllll}
\hline$\theta\left(^{\circ}\right)$ & 15 & 30 & 45 & 60 & 75 & Mean value \\
\hline$\tau_{1}(\mathrm{Mpa})$ & 12.5 & 14.8251 & 12 & 11.4932 & 10.634 & 12.290 \\
$G_{c}\left(K J / m^{2}\right)$ & 10.3597 & 8.7914 & 9.8667 & 11.8374 & 9.9785 & 10.166 \\
\hline
\end{tabular}

surface accounts for $32.36 \%$, the energy for the friction accounts for $51.14 \%$, while the energy spent on the chip fracture accounts for $16.5 \%$. It can be found that the new surface energy in CFRP orthogonal cutting tends to decrease with increasing $\theta$. For all three fiber orientations, the energy consumed in tool-chip friction is the greatest, and its value increases with increasing $\theta$. This might be caused by the increasing friction coefficient at the interface of tool-chip for different $\theta$.

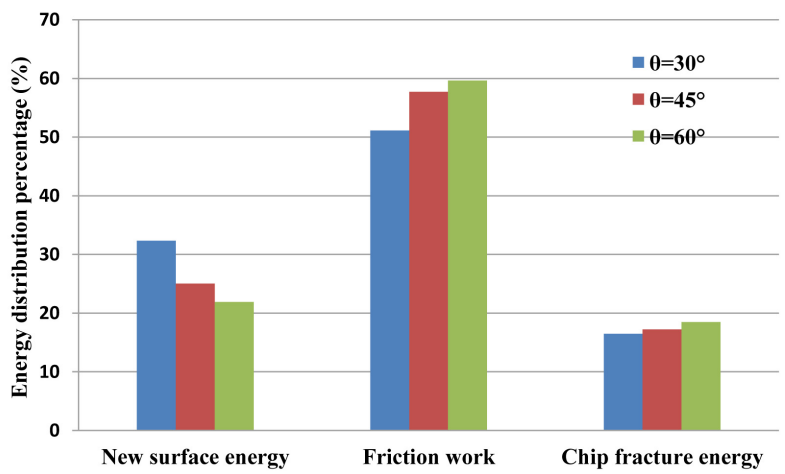

Fig. 10 Effect of fiber angle on the energy distribution in CFRP cutting process (cutting speed: $0.5 \mathrm{~m} / \mathrm{min}$, DOC: $0.1 \mathrm{~mm}$, and rake angle: $5^{\circ}$ )

\section{Conclusions}

In this work, a new approach is proposed for predicting UDCFRP fracture toughness based on the Williams model. Energy conservation analysis is carried out which considers the energy consumption for creating new machined surface. The fracture toughness of separation between segments in block chips in CFRP orthogonal cutting process has also been discussed. The following conclusions are drawn:

1. Both fiber orientation $\theta$ and DOC have strong influence on the chip formation mechanism and chip morphology. The chips are powder-like or ribbon-like, when the DOC is small ( $\leq 0.1 \mathrm{~mm}$ in this paper), but become blocky with increasing DOC.

2. In the case of $15^{\circ} \leq \theta<75^{\circ}$, chips are produced by the matrix-fiber interface shearing along the fiber direction; and when the fiber angle is over $75^{\circ}$, the chip is yielded due to bending fracture and might lead to the fiber bouncingback in the cutting process, and this would degrade the surface roughness of machined surface.
3. The fracture toughness and shear strength of the workpiece material can be determined from line fitting of $F_{c} / a_{w}-$ $\left(F_{t} / a_{w}\right) \tan \theta$ and $a_{c}(\tan \theta+1 / \tan \theta)$ when the fiber orientation $\theta$ is between $15^{\circ}$ and $75^{\circ}$, the fracture toughness of new machined surface $G_{c}$ is independent of $\theta$.

4. The energy consumption during the CFRP machining process consists of three factors (new surface energy, friction and chip fracture energy) and the tool-chip friction energy plays a predominant role, then is new surface energy and chip fracture energy. Energy consumption for creating new machined surface decreases with increasing $\theta$.

This work provides new insights into the machining process of CFRP, which may in turn help to improve the composite machining process quality control.

Acknowledgements The authors would like to acknowledge the financial support by National Natural Science Foundation of China (Grant No. 51275345 and 51420105007), and National NC Science and Techonology Major Projects (Grant No. 2014ZX04001081).

\section{References}

1. Chibane H, Morandeau A, Serra R, Bouchou A, Leroy R (2013) Optimal milling conditions for carbon/epoxy composite material using damage and vibration analysis. Int J Adv Manuf Technol 68(58):1111-1121

2. Silva D, Teixeira JP, Machado CM (2014) Methodology analysis for evaluation of drilling-induced damage in composites. Int J Adv Manuf Technol 71(9-12):1919-1928

3. Qi Z, Zhang K, Cheng H, Wang D, Meng Q (2015). Microscopic mechanism based force prediction in orthogonal cutting of unidirectional CFRP. Int J Adv Manuf Technol, 1-11.

4. Arul S, Vijayaraghavan L, Malhotra S, Krishnamurthy R(2006) The effect of vibratory drilling on hole quality in polymeric composites. Int J Mach Tools Manuf 46(3):252-259

5. Davim JP, Reis P (2003) Drilling carbon fiber reinforced plastics manufactured by autoclavełexperimental and statistical study. Mater Design 24(5):315-324

6. Soussia AB, Mkaddem A, El Mansori M (2014) Rigorous treatment of dry cutting of FRP-Interface consumption concept: A review. Int J Mech Sci 83:1-29

7. Singh I, Bhatnagar N (2006) Drilling of uni-directional glass fiber reinforced plastic (UD-GFRP) composite laminates. Int J Adv Manuf Technol 27(9-10):870C876

8. Rahm P, Landon Y, Lachaud F, Piquet R, Lagarrigue P (2011)Analytical models of composite material drilling. Int J Adv Manuf Technol 52(5-8):609-617

9. Komanduri R (1997) Machining of fiber-reinforced composites. Mach Sci Technol 1(1):113-152

10. Koplev A, Bunsell A (1980) Machining of fiber-reinforced composites. 3rd International Conference of Advances in Composite Materials $1597-1605$ 
11. Arola D, Ramulu M, Wang D (1996) Chip formation in orthogonal trimming of graphite/epoxy composite. Compos Part A-Appl S $1(1): 113-152$

12. Nayak D, Bhatnagar N, Mahajan P (2005) Machining studies of uni-directional glass fiber reinforced plastic (UD-GFRP) composites part 1: effect of geometrical and process parameters. Mach Sci Technol 9(4):481-501

13. Zitoune R, Collombet F, Lachaud F, Piquet R, Pasquet P (2005) Experiment-calculation comparison of the cutting conditions representative of the long fiber composite drilling phase. Compos Sci Technol 65(3):455-466

14. Zhou L, Hou N, Huang S, Xu L (2014) An experimental study on formation mechanisms of edge defects in orthogonal cutting of SiCp/Al composites. Int J Adv Manuf Technol 72(9-11):1407-1414

15. Everstine G, Rogers T (1971) A theory of machining of fiberreinforced materials.J Compos Mater 5(1):94-106

16. Bhatnagar N, Ramakrishnan N, Naik N, Komanduri R (1995) On the machining of fiber reinforced plastic (FRP) composite laminates.Int J Mach Tools Manuf 35(5):701-716

17. Zhang L, Zhang H, Wang X (2001) A force prediction model for cutting unidirectional fibre-reinforced plastics.Mach Sci Technol 5(3):293-305

18. Jahromi AS, Bahr B (2010) An analytical method for predicting cutting forces in orthogonal machining of unidirectional composites.Compos Sci Technol 70(16):2290-2297

19. Ernst H, Merchant ME (1941) Chip formation, friction and finish. Cincinnati milling machine Company

20. Rahamathullah I, Shunmugam M (2014) Mechanistic approach for prediction of forces in micro-drilling of plain and glass-reinforced epoxy sheets. Int J Adv Manuf Technol 75(58):1177C1187
21. Atkins A (2003) Modelling metal cutting using modern ductile fracture mechanics: quantitative explanations for some longstanding problems.Int J Mech Sci 45(2):373-396

22. Astakhov VP, Xiao X (2008) A methodology for practical cutting force evaluation based on the energy spent in the cutting system.Mach Sci Technol 12(3):325-347

23. Williams J, Patel Y, Blackman B (2010) A fracture mechanics analysis of cutting and machining. Eng Fract Mech 77(2):293-308

24. Wang X, Zhang L (2003) An experimental investigation into the orthogonal cutting of unidirectional fibre reinforced plastics. Int J Mach Tools Manuf 43(10):1015-1022

25. Rao GVG, Mahajan P, Bhatnagar N (2007) Machining of UDGFRP composites chip formation mechanism. Compos Sci Technol 67(11):2271-2281

26. Ramulu M, Kim D, Choi G (2003) Frequency analysis and characterization in orthogonal cutting of glass fiber reinforced composites. Compos Part A-Appl S 34(10):949-962

27. Patel Y, Blackman B, Williams J (2009) Determining fracture toughness from cutting tests on polymers. Eng Fract Mech 76(18):2711-2730

28. Wang B, Liu Z, Yang Q (2013) Investigations of yield stress, fracture toughness, and energy distribution in high speed orthogonal cutting. Int J Mach Tools Manuf 73:1-8

29. Shet C, Chandra N (2002) Analysis of energy balance when using cohesive zone models to simulate fracture processes. J Eng Mater Technol 124(4):440-450

30. Rao GVG, Mahajan P, Bhatnagar N (2007) Micro-mechanical modeling of machining of FRP composites-Cutting force analysis. Compos Sci Technol 67(3-4):579-593 